\title{
Study on Preparation and Performance of High Performance Pervious Concrete
}

\author{
Zhigang Niu* and Pinghua Zhu \\ Department of Environmental and Safety Engineering, Changzhou University, Changzhou, China \\ ${ }^{*}$ Corresponding author
}

\begin{abstract}
The permeability, compressive strength, splitting tensile strength and frost resistance of high performance pervious concrete specimens with different pore size and distribution were studied under different curing mechanisms. The results show that the permeability coefficient of curing $7 \mathrm{~d}$ test specimens are not very different from that of curing $28 \mathrm{~d}$ test specimens; the permeability coefficient increases with the increase of porosity; the compressive strength and splitting tensile strength decrease with the increase of porosity; in the early stage of high performance concrete curing, adequate humidity is conducive to strength growth; the splitting tensile strength measured in the test is 1/12 1/15 of compressive strength; When $5 \%$ sodium chloride solution is used as a freeze-thaw medium, the permeability and compressive strength of the concrete after freeze-thaw changed more obviously.
\end{abstract}

Keywords-high performance pervious concrete; maintenance mechanism; porosity; permeability coefficient; compressive strength and splitting tensile strength; frost resistance

\section{INTRODUCTION}

With the rapid development of concrete sustainable technology, people not only make use of the structural performance of concrete, but also gradually seek their function, ecology intelligence and other performances[1-3]. As early as more than 100 years ago, some developed countries in Europe, America and Japan began to study and apply pervious concrete. The vibration free forming method has a great demand for the fluidity of concrete. Otherwise, there will be a problem of insufficient density and uneven distribution of aggregate. But the strength of the concrete formed by this method is obviously improved[4]. The early curing of high performance concrete is particularly important because its early strength growth is the fastest and the later stage is slow [5]. Therefore, the early curing of humidity is very important and the well-maintained concrete has good strength and durability.

In the experiment, high performance pervious concrete specimens with $3-5 \mathrm{~mm}$ pore size and different pore distribution were prepared and three types of curing ways were adopted. The permeability coefficient, compressive strength, splitting tensile strength and frost resistance of high performance pervious concrete were studied by orthogonal test.

\section{EXPERIMENTAL}

\section{A. Raw Material and Methods}

P.O 52.5 grade ordinary portland cement is used. The natural river sand in Changzhou with a particle size less than $4.75 \mathrm{~mm}$ is adopted. The apparent density of silica fume produced by Changzhou Hutang thermal power group is $2759 \mathrm{~kg} / \mathrm{m}^{3}$. The content of $\mathrm{SiO}_{2}$ is $90.0 \%>85 \%$, and loss on ignition is $2 \%<4 \%$. The fly ash is made by the Changzhou thermal power plant. The length of the steel fiber is $35 \mathrm{~mm}$, the width is $2 \mathrm{~mm}$, and the thickness is $0.8 \mathrm{~mm}$. Water reducer is a polycarboxylic acid high performance water reducer with a water reducing efficiency of 20\%. 25L high-performance pervious concrete requires steel fiber $1950 \mathrm{~g}$, cement $15750 \mathrm{~g}$, fly ash $4500 \mathrm{~g}$, silica fume $2250 \mathrm{~g}$, sand $31175 \mathrm{~g}$, water $4435 \mathrm{~g}$, water reducer $830 \mathrm{~g}$. Distribution of $3 \mathrm{~mm}$-diameter hole is $3 \times 3$ and $4 \times 4$; Distribution of $4 \mathrm{~mm}$-diameter hole is $3 \times 4$ and $4 \times 4$; Distribution of $5 \mathrm{~mm}$-diameter hole is $3 \times 3$ and $3 \times 4$. Wet curing for one week and dry curing for three weeks; wet curing for two weeks and dry curing for two weeks; standard curing for four weeks.

\section{B. Test Method}

According to Darcy's law, the permeability coefficient is determined by Formula 1 [6]. Figure I is a self-made permeability coefficient tester. Compressive strength and splitting tensile strength were tested according to Chinese standard GB/T50081-2002[7].

$$
K_{T}=\frac{Q \times L}{A \times h \times t}
$$

Where $K_{T}$ is permeable coefficient with water temperature at $\mathrm{T}^{\circ} \mathrm{C}, \mathrm{Q}$ is the amount of water seeping in the time $\mathrm{t}$ second, $\mathrm{L}$ is sample thickness, $\mathrm{A}$ is the sample area, $\mathrm{h}$ is waterhead, $\mathrm{t}$ is ti me.

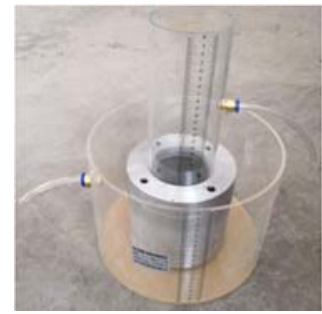

FIGURE I. SELF-DESIGNED PERMEABILITY COEFFICIENT TESTER

\section{RESULTS AND DISCUSSION}

\section{A. Permeability Coefficient}

According to Table I, it is known that the permeability coefficient of high performance pervious concrete has nothing 
to do with curing mechanism. The difference between the permeability coefficient of high performance pervious concrete curing for 7 days and 28 days is very small. It is known that the permeability is almost unchanged from pore forming to curing and the permeability coefficient is almost invariable. The permeability coefficient of high performance pervious concrete increases the increase of porosity, which is a linear relationship, as shown in Figure II.

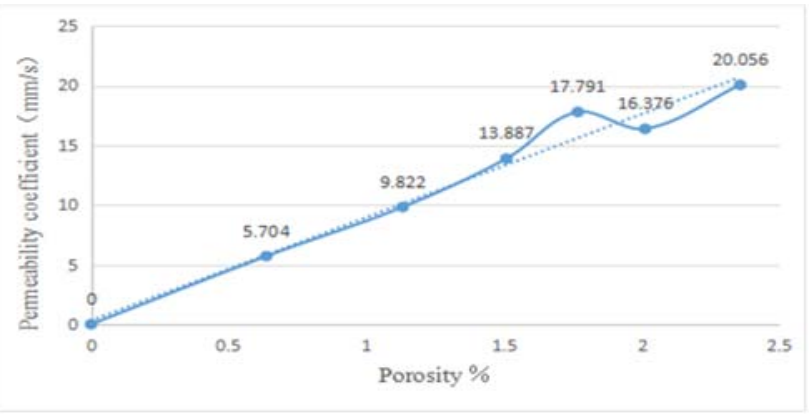

FIGURE II. RELATIONSHIP BETWEEN POROSITY AND PERMEABILITY COEFFICIENT
TABLE I. 7D AND 28D PERMEABILITY COEFFICIENT

\begin{tabular}{ccccccc}
\hline Aperture(mm) & 3 & 3 & 4 & 4 & 5 & 5 \\
\hline Hole distribution & $3 \times 3$ & $4 \times 4$ & $3 \times 4$ & $4 \times 4$ & $3 \times 3$ & $3 \times 4$ \\
7dPermeability mean & 168 & 288 & 409 & 525 & 482 & 590 \\
& 3 & 7 & 7 & 0 & 0 & 6 \\
28dPermeability mean & 168 & 289 & 409 & 524 & 482 & 590 \\
Permeability & 0 & 3 & 0 & 0 & 3 & 7 \\
coefficient(mm/s) & 5.71 & 9.80 & 13.9 & 17.8 & 16.3 & 20.0 \\
\hline
\end{tabular}

B. Compressive Strength

One of the variables in this study is the curing mechanism. The data in Table II can clearly show that the relationship between their compressive strength: wet curing for two weeks and dry curing for two weeks $>$ wet curing for one week and dry curing for three weeks $>$ standard curing for four weeks. The humidity of the early curing environment must be high enough to ensure the normal hydration reaction and the rapid growth of strength and prevent cracking at the same time[8]. High performance concrete increases rapidly in the early stage of curing, which also determines the final strength. Therefore, early curing is particularly important[5]. Proper rise of temperature is beneficial to the late strength of high performance concrete.

TABLE II. COMPRESSIVE STRENGTH

\begin{tabular}{ccccc}
\hline Aperture(mm) & $\begin{array}{c}\text { Hole } \\
\text { distribution }\end{array}$ & $\begin{array}{c}\text { Around the standard under } \\
\text { compressive strength(Mpa) }\end{array}$ & $\begin{array}{c}\text { Two weeks wet and dry } \\
\text { compressive strength(Mpa) }\end{array}$ & $\begin{array}{c}\text { Three weeks of wet and dry } \\
\text { compressive strength(Mpa) }\end{array}$ \\
\hline 0 & --- & 79.2 & 85.2 & 85.9 \\
3 & $3 \times 3$ & 80.8 & 83.3 & 83.1 \\
3 & $4 \times 4$ & 79.1 & 80.6 & 79.8 \\
4 & $3 \times 4$ & 79.5 & 77.6 & 76.5 \\
4 & $4 \times 4$ & 66.4 & 80.0 & 79.2 \\
5 & $3 \times 3$ & 74.7 & 78.0 & 77.7 \\
5 & $3 \times 4$ & 72.0 & \\
\hline
\end{tabular}

According to the above principles and references, the compressive strength of the high performance pervious concrete block is analyzed under the different curing mechanism. The condition of standard curing is humidity $95 \%$, temperature $(20 \pm 2){ }^{\circ} \mathrm{C}$; wet curing is to put the test blocks in water and the temperature is the same as that of the standard; dry curing is the test blocks in the natural environment. In wet curing for two weeks and dry curing for two weeks, which is more conducive to the increase of the strength of the high performance concrete. The test block under the three curing mechanisms showed the same phenomenon. The greater the porosity, the lower the compressive strength. The relationship between them is shown in Figure III.

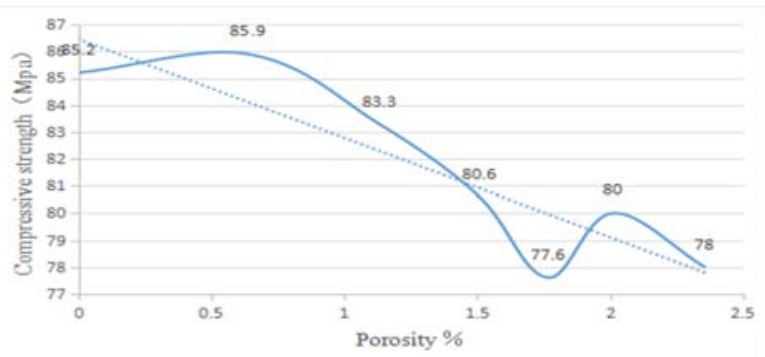

FIGURE III. RELATIONSHIP BETWEEN COMPRESSIVE STRENGTH

\section{Tensile Splitting Strength}

According to Table III, the regulation of the splitting tensile strength in the test is similar to that of its compressive strength. The specific performance is that the splitting tensile strength of standard curing blocks is slightly lower; that of the test blocks with wet curing for two weeks and dry curing for two weeks was the highest; the splitting tensile strength decreased with the increase of porosity. Comparing with Tables II and III, it is found that the splitting tensile strength decreases with the decrease of compressive strength. According to the calculation, the splitting tensile strength is about $1 / 12 \sim 1 / 15$ of the compressive strength. The reason is related to the strength growth law of high performance pervious concrete. 
TABLE III. TENSILE SPLITTING STRENGTH

\begin{tabular}{ccccc}
\hline Aperture $(\mathrm{mm})$ & $\begin{array}{c}\text { Hole } \\
\text { distribution }\end{array}$ & $\begin{array}{c}\text { Peripheral standard tensile } \\
\text { splitting strength (Mpa) }\end{array}$ & $\begin{array}{c}\text { Two weeks wet and dry tensile } \\
\text { splitting strength (Mpa) }\end{array}$ & $\begin{array}{c}\text { One weeks wet and theer weeks dry } \\
\text { tensileSplitting Strength (Mpa) }\end{array}$ \\
\hline 0 & --- & 6.00 & 6.30 & 6.08 \\
3 & $3 \times 3$ & 6.12 & 6.39 & 6.22 \\
3 & $4 \times 4$ & 6.07 & 6.31 & 6.10 \\
4 & $3 \times 4$ & 5.90 & 6.03 & 6.06 \\
4 & $4 \times 4$ & 5.08 & 5.73 & 5.60 \\
5 & $3 \times 3$ & 5.52 & 5.84 & 5.81 \\
5 & $3 \times 4$ & 5.44 & 5.60 & 5.55 \\
\hline
\end{tabular}

D. Frost Resistance

specimens before and after freezing and thawing are shown in

The permeability coefficients of the two sets of concrete Table IV.

TABLE IV. CHANGE OF PERMEABILITY COEFFICIENT BEFORE AND AFTER FREEZING AND THAWING WITH CLEAR WATER AND 5\% SODIUM CHLORIDE SOLUTION AS MEDIUM SOLUTION

\begin{tabular}{cccccccc}
\hline Porosity(\%) & 0 & 0.636 & 1.131 & 1.508 & 1.767 & 2.011 & 2.356 \\
\hline $\begin{array}{c}\text { Average permeability before freezing and } \\
\text { thawing(mm/s) }\end{array}$ & 0 & 5.19 & 9.01 & 12.98 & 15.11 & 16.35 \\
$\begin{array}{c}\text { Average permeability coefficient after freezing and } \\
\text { thawing with clear water (mm/s) }\end{array}$ & 0 & 5.18 & 8.86 & 13.05 & 14.95 & 16.25 & 19.10 \\
$\begin{array}{c}\text { Average permeability coefficient after freezing and } \\
\text { thawing with 5\% sodium chloride solution (mm/s) }\end{array}$ & 0 & 4.98 & 8.31 & 12.51 & 15.22 & 15.82 & 18.10 \\
\hline
\end{tabular}

The average change of permeability coefficient was The compressive strength of three groups of high $0.067 \mathrm{~mm} / \mathrm{s}$ before and after freezing and thawing with water as medium and the average change rate is $0.52 \%$; the average change of permeability coefficient was $0.63 \mathrm{~mm} / \mathrm{s}$ before and after freezing and thawing with $5 \%$ sodium chloride solution as medium and the average change rate is $4.785 \%$. From the comparison between the two groups of data, it can be found that the permeability coefficient of concrete with $5 \%$ sodium chloride solution as the freezing and thawing medium decreased more obviously. performance pervious concrete specimens were measured respectively. The first group was unfreeze-thawing specimens, the second group was specimens with pure water as freezing-thawing medium, the third group was specimens with $5 \%$ sodium chloride solution as the freezing-thawing medium. It can be seen from the above tables that the strength changes with different medium solutions are different after freezing and thawing. And the strength change of blocks with 5\% sodium chloride solution as medium is more obvious. The results are shown in Table $\mathrm{V}$.

TABLE V. COMPARISON OF THREE COMPRESSIVE STRENGTHS

\begin{tabular}{cccccccc}
\hline Porosity(\%) & 0 & 0.636 & 1.131 & 1.508 & 1.767 & 2.011 & 2.356 \\
\hline $\begin{array}{c}\text { The first group of average } \\
\text { compressive strength(Mpa) } \\
\begin{array}{c}\text { The second group average } \\
\text { compressive strength(Mpa) }\end{array}\end{array}$ & 85.4 & 84.2 & 78.5 & 81.2 & 86.2 & 80.3 & 79.0 \\
$\begin{array}{c}\text { The third group average } \\
\text { compressive strength(Mpa) }\end{array}$ & 83.9 & 80.1 & 75.4 & 80.2 & 83.3 & 78.5 & 69.3 \\
\hline
\end{tabular}

IV. CONCLUSIONS

The difference of permeability coefficient between curing for $7 \mathrm{~d}$ and $28 \mathrm{~d}$ for high performance pervious concrete is very small. The permeability coefficient increases with the increase of porosity.

The compressive strength and splitting tensile strength of the concrete under wet curing for two weeks and dry curing for two weeks are relatively high, indicating that sufficient humidity is very important for the early curing stage of high performance concrete.

The greater the porosity is, the lower the compressive strength and the splitting tensile strength are,where is a linear relationship.

The splitting tensile strength is about 1/12 1/15 of compressive strength.

There is a certain gap in the data change of different freeze-thaw media after freezing and thawing. The change of permeability coefficient and compressive strength of the concrete with $5 \%$ sodium chloride solution as a freeze-thaw medium after freezing and thawing is more obvious.

\section{ACKNOWLEDGEMENTS}

This research was financially supported by the National 
Natural Science Foundation of China (No.51678081) and Postgraduate Research \& Practice Innovation Program of Jiangsu Province (SJCX17_0710).

\section{REFERENCES}

[1] V. C. Li, Y. M. Lin, Y. W. Chan, etal, Feasibility study of a passive smart se1f healing cementitious cocomposite, Composites Pan B: Engineering. 29(1998)819-827.

[2] C. M. Dry, Three designs for the internal release of sealants adhesives and waterproofing chemicals into concrete to reduce permeability, Cement and Concrete Research.30(2000)1969 - 1977.

[3] M. Sun, Z. Li, Q. Liu, etal, A study an thermal self dissociative and self adaptive smart concrete structures, Cement and Concrete Research.30(2000)1251-1253.

[4] J. H. Hao, Porous concrete raw material technology infancy, molding method and aggregate gradation design, Highway Traffic Science and Technology Applied Technology Edition.3 (2007)46-50.

[5] M. H. Yao, B. G. Zhan, L. Hui, High-performance concrete curing, Industrial Construction.17 (2006) 70-72+90.

[6] J. Yang, submitted to Tsinghua University Press(2001)

[7] GB/T50081- 2002: Standard for test method of mechanical properties on ordinary concrete, Construction Industry Publications, China, BJ(2003)

[8] Z. W. Wu, H. Z. Lian: High-performance concrete, Beijing: China Railway Publishing House.23 (1999)306-311. 